\title{
ANÁLISIS Y RECOMENDACIONES SOBRE SOFTWARE PARA ARCHIVOS DE IMÁGENES
}

\author{
Javier Navas-Millán y Antonio-Ángel Ruiz-Rodríguez
}
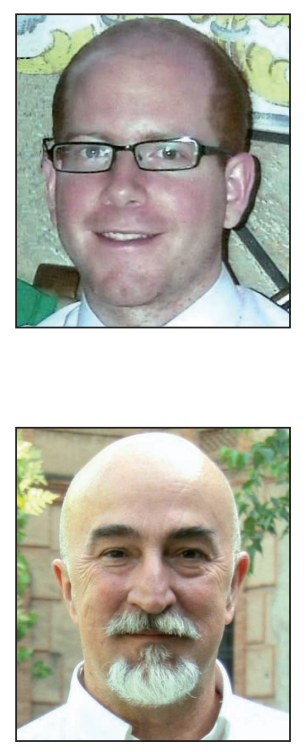

Javier Navas-Millán es ingeniero técnico en informática de sistemas y licenciado en comunicación audiovisual por la Universidad de Granada. Se inició en el mundo de la investigación al cursar el máster en información y comunicación científica, finalizando los estudios con la tesis de máster: "Evaluación y propuesta de software para el tratamiento, descripción y puesta en valor de un archivo fotográfico en soporte electrónico". En la actualidad trabaja en Granada en diversos proyectos relacionados con la informática y la comunicación.

Facultad de Comunicación y Documentación Campus Universitario de Cartuja Edificio Máximo. 18071 Granada ervijanm@gmail.com

Antonio-Ángel Ruiz-Rodríguez es profesor en la Universidad de Granada (UGR) desde hace más de treinta años. Sus investigaciones parten de la archivística tradicional y, pasando por estudios sobre documento electrónico y normas de descripción, se centran en los últimos años en la recuperación de documentos fotográficos. Dirigió la primera tesis doctoral sobre fondos fotográficos de prensa en la UGR marcando una línea de investigación que se ha extendido en seis master o doctorados de distintas universidades generando monografías y publicaciones sobre tecnologías de conservación, difusión e identificación de imágenes fotográficas. En la actualidad es decano de la Facultad de Comunicación y Documentación de la UGR.

Facultad de Comunicación y Documentación Campus Universitario de Cartuja Edificio Máximo. 18071 Granada aangel@ugr.es

\section{Resumen}

Mediante la investigación en internet del mercado actual de los programas relacionados con el manejo de imágenes, se intentan buscar las mejores soluciones software para la descripción, valoración y difusión de un archivo fotográfico. Con la experiencia obtenida del uso y configuración de estos programas y con la valoración del cumplimiento de los requisitos establecidos previamente, se ha elaborado una lista de los que resultan más versátiles o adaptables a diferentes medios y requisitos, y con capacidad de crecer si el proyecto lo requiere. Además se aportan los criterios y recomendaciones para determinar cuáles de ellos son mejores para cada tipo de archivo, como puede ser el de una institución pública o privada, una agencia, o un archivo personal.

\section{Palabras clave}

Catalogación, Descripción, Metadatos, Fotografía, Imágenes, Tratamiento, Software, Archivos.

\section{Title: Analysis and recommendations on software for image archives}

\section{Abstract}

Using internet research to study the current market of programs related to image management, we searched for the best software solutions for the description, dissemination and promotion of a photographic archive. With the experience obtained from using and configuring these programs and with an evaluation using previously established requirements, a list of the most adaptable and versatile software having the added value of being capable of expansion has been elaborated. In addition, we have been able to contribute to establishing the criteria and recommendations to determine which of them are better for each type of archive, for a public or private institution, an agency, or a personal archive.

\section{Keywords}

Cataloguing, Description, Metadata, Photographs, Images, Treatment, Software, Archives.

Navas-Millán, Javier; Ruiz-Rodríguez, Antonio-Ángel. "Análisis y recomendaciones sobre software para archivos de imágenes". El profesional de la información, 2011, julio-agosto, v. 20, n. 4, pp. 474-480. \section{http://dx.doi.org/10.3145/epi.2011.jul.17}

Artículo recibido el 26-04-11

Aceptación definitiva: 25-05-11 


\section{Objetivo}

El objetivo principal de este trabajo es encontrar las mejores soluciones software para la descripción, puesta en valor y difusión de un archivo fotográfico. Para ello, se ha elaborado una lista de los programas de tratamiento y archivado de imágenes existentes en el mercado para, mediante el análisis y evaluación de sus características, encontrar los más versátiles o adaptables a diferentes medios y requisitos, y con capacidad de crecer si el proyecto lo requiere.

\section{Introducción}

Las imágenes digitales son el soporte fotográfico más extendido en la actualidad, gracias al bajo precio de producir nuevas fotografías, la facilidad de visionado y la cada vez mayor calidad.

Con esa facilidad de producción, los archivos fotográficos pueden crecer hasta decenas de miles de fotografías ordenadas en carpetas de ordenador, donde acceder a las mejores del archivo o simplemente buscar una imagen cuesta mucho trabajo si no hay detrás un esfuerzo de catalogación y documentación previo. Así surgieron los primeros programas de indexación y, con el tiempo, los primeros estándares de creación de metadatos para clasificar las imágenes y leerlas desde distintos programas.

\section{Tipos de metadatos}

Por metadato entendemos un tipo de dato que nos da información sobre una imagen, y que puede incluso formar parte de la misma, sin ser la imagen en sí. Hay 3 tipos:

- Tipo 1: asociados a las propiedades del fichero y generados por el dispositivo que lo crea. Ejemplo: formato, tamaño, fecha de creación, etc. Aquí se puede incluir el formato EXIF (exchangeable image file format), utilizado por la mayoría de dispositivos actuales.

- Tipo 2: introducidos de forma manual a posteriori en las imágenes, las documentan con información sobre su contenido, lugar o los datos del autor. Esta información es de gran utilidad para los creadores, pero también para potenciales destinatarios como publicaciones, agencias o incluso compradores. El estándar más extendido es el IPTC, creado por el International Press Telecommunications Council.

- Tipo 3: agrupaciones de alto nivel, usadas para clasificar las imágenes según su calidad, o en contenedores temáticos como álbumes y catálogos. Un grupo de metadatos estándar es el XMP, introducido por Adobe, que cuenta con campos para establecer puntuaciones y etiquetas de color a las imágenes. Además permite registrar la historia de la fotografía desde que fue tomada o escaneada hasta su edición y ensamblado en el recurso final. En 2005 se lanzó la primera versión en colaboración con el IPTC, llamada IPTC Core Schema for XMP, cuya novedad era la posibilidad de unir los metadatos dentro de un fichero paralelo de extensión XMP que abría nuevas posibilidades.

\section{Investigación}

Existen diferentes tipos de archivos, como pueden ser los personales, de instituciones públicas y privadas o de empre- sas relacionadas con la comunicación (periódicos, agencias, etc.), pero para poder definir los criterios que definan qué programas son más recomendables, hay que buscar al menos su aplicación a un "archivo tipo".

Se contemplan archivos que contengan al menos 5.000 fotografías, pero que pueden ir creciendo hasta más allá de las 100.000, con cualquier formato digital.

Respecto a las imágenes, se establece un tamaño medio de 5 megapíxeles (alrededor de 2-3 Mbytes), con imágenes que podrían haber sido creadas desde un móvil hasta una cámara profesional, por lo que como mínimo se necesitaría una capacidad de almacenamiento de 15 GB.

El archivo debe ser dinámico y permitir que los usuarios contribuyan con sus creaciones a través de la Red. Los administradores añadirán o retirarán imágenes del catálogo para tenerlo en continua renovación. Para cada nueva imagen se pone en marcha un proceso de adecuación, formateo y adaptación al archivo, para acomodarla a los estándares del mismo.

A la vista de las características que tendría el archivo, es necesario un software que cumpla los siguientes requisitos:

- software libre o precio no muy alto;

- facilidad de uso e instalación;

- suficiente documentación y soporte técnico;

- multiplataforma y varios idiomas;

- conexión online, para poder consultarlo desde cualquier parte del mundo;

- posibilidad de crear plantillas para rellenar los campos;

- posibilidad de editar y añadir nuevos metadatos;

- poder renombrar o guardar metadatos para conjuntos de imágenes;

- gestionar la colección de imágenes en CD, DVD o discos duros externos, para facilitar las copias de seguridad o el traslado de la colección;

- mantenimiento y actualizaciones.

\section{El archivo debe ser dinámico y permitir que los usuarios contribuyan con sus creaciones a través de la Red}

Para evaluar estos criterios y dar una valoración numérica final a cada programa, se puntúa del 1-5 cada requisito, haciendo pesar un $75 \%$ los más importantes frente al $25 \%$ del resto.

El siguiente paso, es buscar en internet los programas que se puedan adaptar a estos requisitos. Tras las primeras búsquedas, podemos clasificar los programas relacionados con la imagen y los metadatos en 2 tipos distintos:

- Programas capaces de visualizar imágenes digitales de muchos tipos y mostrar sus metadatos asociados, pero con poca funcionalidad para editarlos y catalogarlos, por lo que se descartan. Algunos de estos programas son: Adobe Bridge, Canon Digital Photo Professional, Nikon View, BreezeBrowser, Photo Mechanic, Pixvue, iTag, Windows Vista Photo Gallery, Picasa, XnView, Mapivi, iPhoto, Fast Stone Image Viewer, Lphoto, Kphoto Album, etc. 
- Programas de archivo y catalogación que pueden editar todos los metadatos y crear nuevos. Son de mayor magnitud, e incorporan más opciones a la hora de archivar, catalogar e indexar las imágenes, además de tener bases de datos para poder realizar búsquedas en grandes catálogos. La mayoría permite guardar la información de los campos IPTC para varias imágenes a la vez y crear plantillas para rellenar los campos más rápidamente. Algunos de los más representativos son: ACDSee, Adobe Lightroom, Apple Aperture, DigiKam, FotoStation, IMatch, iViewMicrosoft Expression Media, Kalimages, ThumbsPlus, XTF y Zoner Photo Studio Pro.

\section{Análisis de los programas}

Para cada uno de ellos se realizó una ficha técnica con información como: empresa, versión, año de lanzamiento y precio, metadatos que permite manejar, y aspectos como su facilidad de instalación o el diseño de la interfaz.

Después se realizó la instalación, configuración y uso para un archivo pequeño (unas 1.000 fotografías), como el que le daría un usuario tipo, tratando de ver sus ventajas y deficiencias. En el caso de programas no gratuitos, usamos los software de prueba que los fabricantes tienen alojados en sus portales web.

Finalmente se plantea una conclusión explicando las fortalezas y debilidades de cada uno y estableciendo la valoración numérica del software a partir de los criterios fijados.

A continuación se comentan brevemente algunas características de cada uno de ellos, incidiendo más en los que finalmente se han elegido:

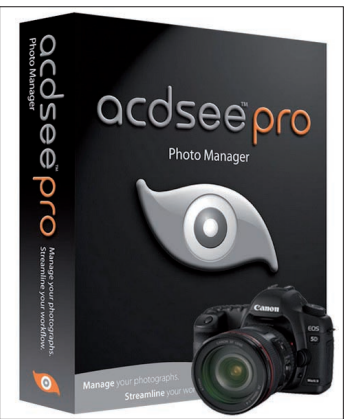

\section{ACDSee}

\section{http://www.acdsee.com}

Cuenta con gran popularidad como visor de imágenes desde hace una década, por ser intuitivo y fácil de usar.

Permite sincronización con base de datos online, de menos de 25GB de tamaño, y quizá está algo limitado a la hora de manejar ficheros RAW y campos IPTC. Su precio ronda los $150 €$ para la versión completa. Está disponible en castellano y para plataforma PC y Mac. La última versión es la ACDSee Pro 4, que implementa la funcionalidad para trabajar con ficheros RAW.

\section{Adobe Lightroom}

http://help.adobe.com/es_ES/Lightroom/3.0/Using/index. html

Desarrollado por Adobe Systems como asistente para fotógrafos profesionales, intenta cubrir todo el proceso que va desde la descarga de una fotografía hasta su publicación. Es capaz de manejar miles de imágenes digitales y hacer el trabajo de postproducción. Da muchas facilidades a la hora de crear álbumes web, modificar cualquier metadato y crear nuevos. La interfaz está muy cuidada y además, el precio no supera los $100 €$.

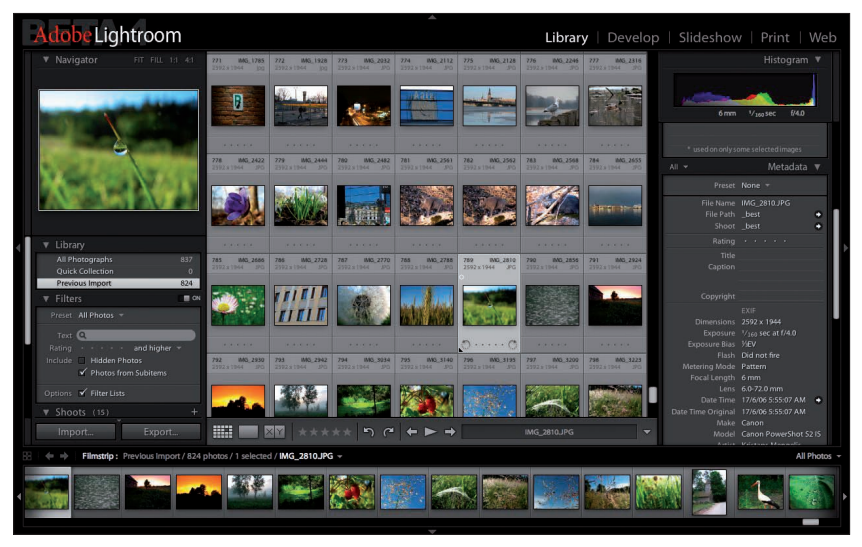

La información de las imágenes que guarda Lightroom se almacena con el estándar XMP, creado en XML. Los metadatos creados en otros formatos se sincronizan y describen con XMP para que se puedan ver y gestionar con mayor facilidad. En el caso de ficheros RAW, el XMP no se almacena en el archivo original, sino que se incluye en otro archivo llamado sidecar.

Lightroom utiliza un catálogo para controlar la ubicación de los archivos y guardar la información sobre sus metadatos y los ajustes y cambios que se han realizado. También permite añadir marcas de agua a las fotografías, y visualizar los metadatos de copyright, además de poder añadir información geográfica.

Como inconveniente se observa el requerimiento de muchos recursos de hardware, y que la curva de aprendizaje es lenta, por la cantidad de funciones que posee.

\section{Buscar una imagen cuesta mucho traba- jo si no hay detrás un esfuerzo de catalo- gación y documentación previo}

\section{Apple Aperture}

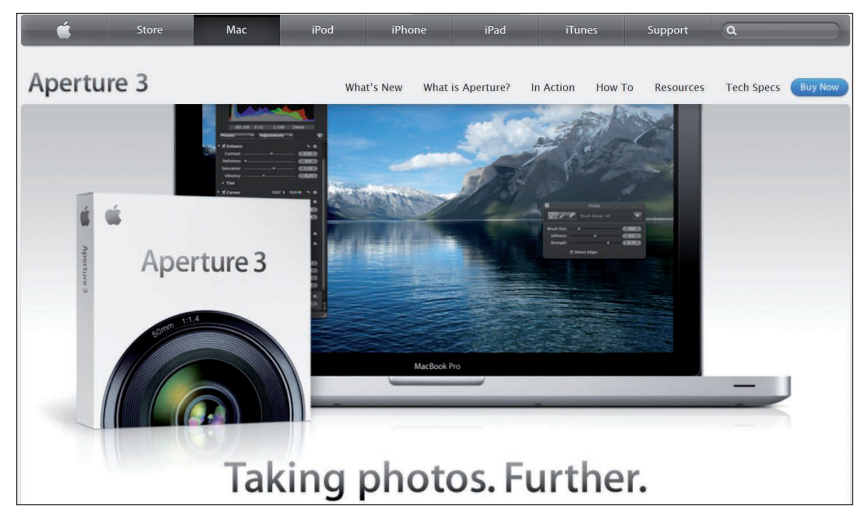

http://www.apple.com/es/aperture

Diseñado por Apple. Por sus herramientas se asemeja al Adobe Lightroom. También trabaja con imágenes RAW, y da la posibilidad de hacer álbumes de fotos en internet, exportándolas directamente a la Web. Su gran limitación es que sólo está disponible para Mac, por lo que no se puede recomendar salvo para usuarios habituales de esta plataforma. 
Su precio ronda los $200 €$. Es uno de los mejores programas de catalogación y archivo de imágenes.

\section{Digikam}

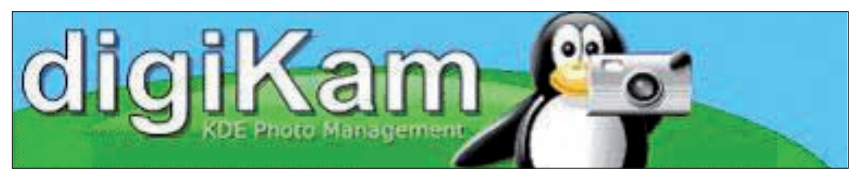

http://www.digikam.org

Software libre diseñado para fotógrafos profesionales que permite editar, organizar, etiquetar y hacer búsquedas en colecciones de fotografías, con el sistema operativo Linux. Proporciona soporte para metadatos IPTC y es capaz de manejar imágenes RAW, aunque tiene carencias a la hora de crear nuevos metadatos que no estén en su catálogo. Para extender sus funciones existen plugins muy variados. Una de sus ventajas es que es gratuito, y quizá un inconveniente podría ser la dificultad de instalación para un usuario no experto. Actualmente va por la versión 1.6, y es posible instalarlo en otros sistemas operativos como integrante de la plataforma KDE.

Este programa es quizá la mejor alternativa para Linux a las herramientas existentes tanto para PC como para Mac. Una de sus ventajas es que una gran comunidad de desarrolladores trabaja en su mejora y actualización, por lo que cada vez incorpora más funciones. Una de las futuras posibilidades será el etiquetado de imágenes mediante reconocimiento facial, que probablemente en 2011 esté disponible con la incorporación de la biblioteca Libface.

\section{Fotostation Pro 7}

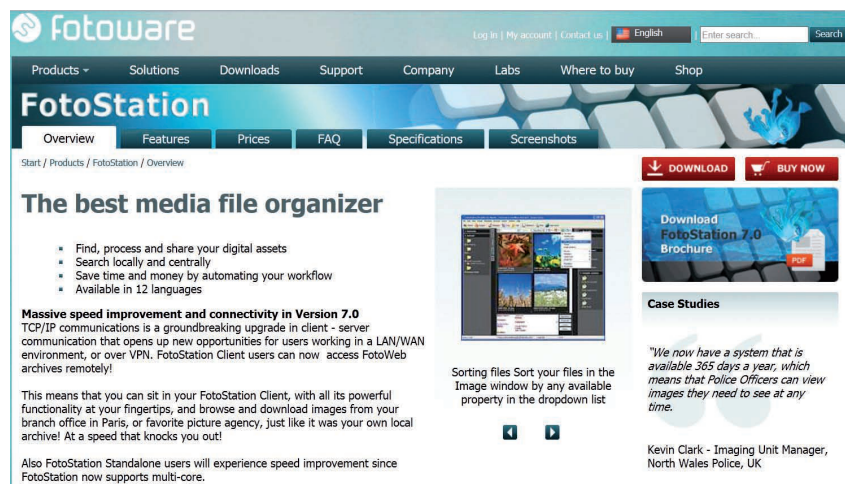

http://www.fotoware.com

Es una de las herramientas más conocidas debido a su presencia en los productos de Nikon. Actualmente la versión más avanzada es la 7 Pro. Está orientado al trabajo de agencias y fotógrafos de prensa, y se puede usar en archivos fotográficos corporativos que funcionan en red.

La integración de XMP es buena y permite trabajar con grandes cantidades de imágenes de una sola vez. El soporte de ficheros RAW es limitado y le faltan opciones de configuración. Además tarda en cargar en pantalla las imágenes en miniatura.

La licencia de la versión 7 Pro cuesta $489 €$ y está disponible para PC y Mac. Al igual que Apple Aperture, es muy potente, aunque su alto precio hace descartarlo para la mayoría de usuarios domésticos.

\section{IMatch}

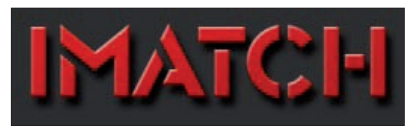

http://www.photools.com

Fue desarrollado por el programador alemán Mario Westphal, que comercializa su producto en internet a $49 €$. Es fácil de instalar y la interfaz de usuario es muy amigable, con ventanas y explorador de carpetas de tipo Windows.

La capacidad de la base de datos es casi ilimitada: Hay archivos funcionando con IMatch que contienen más de un millón de fotografías. El sistema permite editar la información de una o de miles de fotos simultáneamente.

El hecho diferenciador de IMatch está en que tiene un sistema de categorías dinámicas que permite asignar cada una de las imágenes a un número ilimitado de categorías, por lo que podremos recuperarlas de un conjunto virtual de carpetas u otro.

Uno de los modos de búsqueda más sorprendente es el de buscar por tonos de color y su distribución en la imagen. El programa permite incluso dibujar un boceto de la foto que se quiere localizar.

Permite la creación de álbumes web, lo que puede servir para publicar las fotos de una determinada carpeta virtual o categoría.

En conclusión, se puede decir que IMatch no es tan potente como otros programas mucho más caros, pero con él se puede hacer casi todo lo que aquí se plantea y es compatible con los formatos más usados, por lo que su relación calidad/precio es excelente. Es bastante configurable, además de existir una documentación muy completa sobre el mis mo, por lo que es recomendable para archivos personales.

Como inconvenientes: sólo está disponible en inglés y para Windows, y tiene una curva de aprendizaje lenta aunque a la larga provechosa.

Los metadatos son de gran utilidad para los creadores, pero también para potenciales destinatarios, como publicaciones, agencias o particulares

\section{iView Media Pro}

\section{http://www.iview-multimedia.com/}

Durante muchos años fue una de las aplicaciones más populares para Mac, aunque posteriormente comenzó a estar disponible también para PC. Se trata de un programa bastante intuitivo de usar y que cuenta con un sistema de organización por catálogos y categorías independientes. Es compatible con los formatos RAW y trabaja con los campos estándar IPTC. Como los demás, ofrece la posibilidad de realizar retoques básicos en las imágenes y crear audiovisuales sencillos.

En 2006 iView fue comprado por Microsoft, dando lugar al Microsoft Expression Media, que fue integrado en la suite 
Microsoft Expression Studio, disponible por 300€. Microsoft no da soporte a los antiguos usuarios de iView, lo que hace descartarlo, a pesar de su notable interés.

\section{Kalimages}

\section{http://peccatte.karefil.com/Kalimages/ES}

Creado por la empresa francesa Soft Experience, que utiliza tecnología de la base de datos SQLite. Se puede comprar por $47 €$ en su web. Tiene algunas carencias para añadir nuevos metadatos y categorías, y realizar una conexión online al catálogo. Su bajo precio es un punto a favor, aunque soluciones como IMatch tienen muchas más opciones por el mismo coste. Además, la interfaz es algo arcaica. Pese a todo, para uso doméstico es interesante.

\section{Thumbsplus}

\section{http://www.cerious.com}

Se asemeja mucho a ACDSee e IMatch y cuenta con un buen sistema de catalogación por categorías que facilita la gestión del archivo de fotos. Permite trabajar con los campos IPTC y EXIF. Es compatible con los formatos RAW y ofrece la posibilidad de realizar retoques básicos en las imágenes. El precio de la última versión es de $70 €$, y está disponible en inglés y español para PC.

Está algo limitado a la hora de crear nuevos metadatos. Para uso doméstico es interesante, ya que su licencia no profesional se puede conseguir por poco más de $40 €$. Un punto fuerte sería el buen soporte dado por la empresa Cerious.

\section{$X T F$}

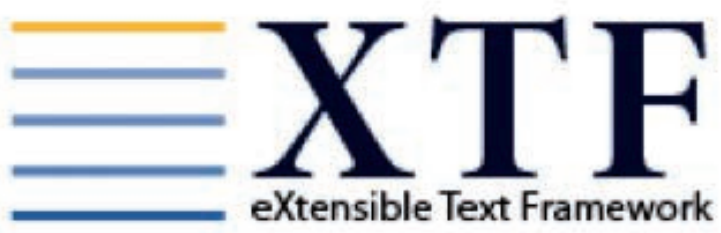

http://xtf.cdlib.org/xtf

Es un programa de software libre, lo que le hace estar en constante desarrollo. Está mantenido por la California Digital Library $(C D L)$, y es la principal tecnología de acceso a muchas colecciones y proyectos en la Red.

La filosofía de este programa es distinta ya que está pensado exclusivamente para la publicación de las imágenes del archivo en la Web.

Cada imagen lleva asociado un fichero XML donde están guardados todos sus metadatos, sean del tipo que sean, lo que permite gran flexibilidad. Ese fichero puede ser exportado a otros programas de archivo y catalogación, y como se trata de texto plano, puede crecer con facilidad. Si se cuenta con un informático para instalarlo, es muy recomendable por las grandes posibilidades al configurarlo añadiendo nuevas funcionalidades, y por el hecho de que muchas instituciones tanto públicas como privadas trabajan con él.

Sólo necesita tener ejecutándose en la máquina un servidor como Tomcat, donde estarán alojadas las imágenes y sus ficheros XML asociados y tener instalada la plataforma Java J2SE. Es fácil de configurar para requerimientos básicos, y permite crear índices de cualquier elemento o atributo XML. La capa de presentación es configurable con XSLT, lo que le permite generar páginas html o xhtml. La unión de XML y XSLT sirve para separar contenido y presentación, aumentando así la eficiencia.

El sistema de XTF está dividido en cuatro componentes, que realizan el trabajo que va desde mostrar la interfaz de usuario para realizar las consultas, hasta la presentación final de los documentos recuperados. Además permite guardar las consultas para que los usuarios puedan acceder directamente a algunas de ellas desde la página web, utilizando comandos booleanos sin dificultad.

El lugar más idóneo para su implantación es el de una fundación pública o privada, que cuente con recursos humanos suficientes. Y como está orientado a la publicación en Web provee buenas herramientas pensadas para este fin, contando además con una interfaz de datos externos que soporta tesauros y sistemas de recomendación. Como no permite visualizar y editar las imágenes, podríamos ayudarnos de programas gratuitos como el XnView.

\section{Zoner Photo Studio}

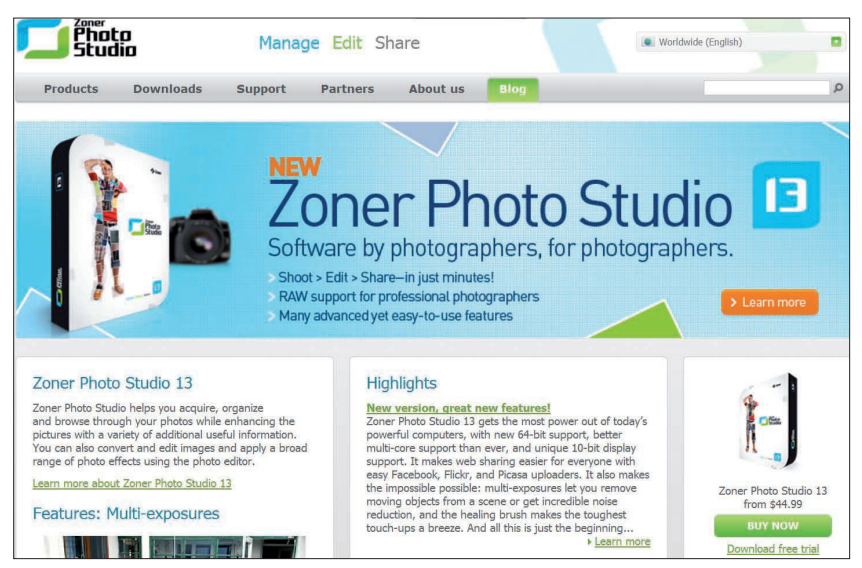

\section{http://www.zoner.com/ww-en}

Es una de las aplicaciones más completas que hay en el mercado ya que abarca todo el proceso desde la descarga de una fotografía digital en el ordenador, hasta su publicación en la Web, pasando por su edición y la creación de metadatos. Ofrece buenas posibilidades para manejar la colección a través de medios y soportes externos. Es recomendable para cualquier usuario ya sea profesional o aficionado, aunque tiene alguna limitación al configurar nuevos metadatos. La última versión en el mercado es la 13 y su precio es de $70 €$.

\section{Buscamos programas versátiles y adap- tables a diferentes medios y requisitos, y con capacidad de crecer si el proyecto lo requiere}

En la tabla 1 se presenta una comparativa entre tres de los programas (uno de software libre, otro profesional con 


\begin{tabular}{|c|c|c|c|c|c|c|}
\hline & \multicolumn{2}{|r|}{$\begin{array}{c}\text { XTF } \\
\text { Calificación / comentario }\end{array}$} & \multicolumn{2}{|r|}{$\begin{array}{l}\text { Adobe Lightroom } \\
\text { Calificación / comentario }\end{array}$} & \multicolumn{2}{|r|}{$\begin{array}{c}\text { IMatch } \\
\text { Calificación / comentario }\end{array}$} \\
\hline $\begin{array}{l}\text { Posibilidad de editar los } \\
\text { metadatos }\end{array}$ & 5 & Sí, en el fichero XML & 5 & Sí & 5 & Puede editar EXIF, IPTC y XMP \\
\hline Facilidad de uso & 2 & $\begin{array}{l}\text { Lo difícil es ponerlo en } \\
\text { marcha. El trabajo diario no es } \\
\text { complicado }\end{array}$ & 4 & $\begin{array}{l}\text { Bastante intuitivo, pero necesita } \\
\text { algo de rodaje porque tiene } \\
\text { muchas funciones y menús }\end{array}$ & 4 & $\begin{array}{l}\text { Curva de aprendizaje lenta, pero } \\
\text { con el tiempo su usabilidad es } \\
\text { satisfactoria }\end{array}$ \\
\hline $\begin{array}{l}\text { Posibilidad de añadir } \\
\text { nuevos metadatos y } \\
\text { categorías }\end{array}$ & 5 & $\begin{array}{l}\text { Sus posibilidades son infinitas, } \\
\text { dependiendo de que podamos } \\
\text { codificar en XML las categorías } \\
\text { que queremos añadir }\end{array}$ & 3 & $\begin{array}{l}\text { Al estar orientado más } \\
\text { a fotógrafos que a } \\
\text { documentalistas, tiene algunas } \\
\text { carencias }\end{array}$ & 3 & $\begin{array}{l}\text { Es muy fácil añadir nuevas } \\
\text { categorías, aunque sólo en los } \\
\text { tipos que el programa soporta }\end{array}$ \\
\hline $\begin{array}{l}\text { Visualización de } \\
\text { imágenes }\end{array}$ & 4 & $\begin{array}{l}\text { El administrador debe usar un } \\
\text { visor de imágenes. El usuario } \\
\text { final las verá en la Web }\end{array}$ & 5 & Total & 5 & $\begin{array}{l}\text { Es posible verlas a partir de las } \\
\text { miniaturas }\end{array}$ \\
\hline Software libre, precio & 5 & Software libre & 2 & $\begin{array}{l}\text { Precio alto, aunque no } \\
\text { totalmente prohibitivo }\end{array}$ & 4 & $\begin{array}{l}\text { Es de los más baratos dentro de } \\
\text { los softwares de pago }\end{array}$ \\
\hline $\begin{array}{l}\text { Conexión online al } \\
\text { archivo }\end{array}$ & 5 & Está orientado para ello & 3 & $\begin{array}{l}\text { Se pueden crear fácilmente } \\
\text { galerías web, pero le faltan } \\
\text { opciones para configurarlas }\end{array}$ & 3 & $\begin{array}{l}\text { Se pueden crear álbumes web, } \\
\text { pero no tiene infinitas opciones } \\
\text { para configurarlos }\end{array}$ \\
\hline Multiplataforma & 5 & $\begin{array}{l}\text { Se puede usar en cualquier } \\
\text { sistema operativo }\end{array}$ & 3 & Sólo Windows & 3 & Sólo Windows \\
\hline $\begin{array}{l}\text { Documentación y } \\
\text { soporte suficiente }\end{array}$ & 3 & $\begin{array}{l}\text { Su soporte es el que da la } \\
\text { comunidad en los foros, y la } \\
\text { existencia de tutoriales }\end{array}$ & 5 & $\begin{array}{l}\text { El fabricante es potente y el } \\
\text { programa es muy usado, por } \\
\text { lo que existe gran cantidad de } \\
\text { información en la Red }\end{array}$ & 4 & $\begin{array}{l}\text { Es un programa bastante } \\
\text { popular y con bastante } \\
\text { información en los foros }\end{array}$ \\
\hline
\end{tabular}

Tabla 1

grandes funcionalidades y otro más barato pero muy recomendable).

\section{Propuesta sobre los programas más adecuados}

Una vez analizados se descartaron los que no tenían alguna funcionalidad imprescindible, no cumplían alguna característica necesaria como el precio bajo o una interfaz amigable, o simplemente había una posibilidad mejor.

Así quedarían sólo 7 de la lista, que son los que se podrían recomendar para los distintos tipos de archivo objeto de estudio: Adobe Lightroom, Apple Aperture, DigiKam, FotoStation Pro, IMatch, XTF y Zoner Photo Studio.

A la vista de los datos y las conclusiones presentadas tras el análisis de cada uno de los programas, se pueden realizar las siguientes puntualizaciones:

- Para un archivo personal o el archivo de una empresa o institución no demasiado grande, se propone IMatch, por ser barato y versátil, o Zoner Photo Studio, por sus enormes posibilidades y por abarcar todo el proceso de descarga, edición, visualización y publicación de la imagen, con un precio ajustado.

- Para un profesional de la fotografía o agencias que puedan permitirse una inversión mayor, el Adobe Lightroom, FotoStation Pro o Apple Aperture (para usuarios de Mac).

- Para una institución pública o privada, o usuarios que tengan arraigada la filosofía del software libre, se propone XTF (si el fin es la publicación en Web y existen recursos humanos para ello), por su flexibilidad para definir cualquier conjunto de metadatos y los ejemplos de su satisfactoria implantación en organismos públicos estadounidenses; o DigiKam, que sería la mejor alternativa a los programas mencionados anteriormente y que al tener trabajando en él a la comunidad del software libre, cada vez será más potente e incorporará las nuevas tecnologías que vayan surgiendo.

No obstante, siempre deberán primar en la decisión final los criterios archivísticos o documentales, buscando la solución que mejor se adapte al sistema de descripción usado.

\section{En la decisión final siempre deberán primar los criterios archivísticos o docu- mentales}

\section{Webs utilizadas \\ ACDSee Photo Software http://www.acdsee.com}

Adobe Photoshop Lightroom 3

http://help.adobe.com/es_ES/Lightroom/3.0/Using/index. $h t m l$

Aperture (Apple)

http://www.apple.com/es/aperture

"Los archivos fotográficos de prensa". Archivistica.net http://www.archivistica.net/archivosprensa.htm

Canonistas.com. Foros de la comunidad de usuarios de cámaras Canon EOS, IXUS y Powershot.

http://www.canonistas.com

Cerious Software (Thumbsplus). http://www.cerious.com

Comunidad de fotógrafos de naturaleza en español. http://www.fotonatura.org 
Digikam

http://www.digikam.org

Fotoware (FotoStation)

http://www.fotoware.com

IPTC (International Press Telecommunications Council). http://www.iptc.org/site/Home

Kalimages software

http://peccatte.karefil.com/Kalimages/ES

Lightroom ES. Tutoriales, trucos y noticias sobre Adobe Lightroom 3 en español.

http://lightroom.fotonatura.org

Microsoft Expression Community

http://expression.microsoft.com/en-us/default.aspx

Organizepictures.com, learn how to organize your digital pictures.

http://www.organizepictures.com

Photools.com, solutions for image management and digital photography (IMatch)

http://www.photools.com

XTF Implementations

http://xtf.cdlib.org/xtf

Zoner Photo Studio

http://www.zoner.com/ww-en

\section{Bibliografía}

Alonso-Fernández, Juan. Digitalización, catalogación y recuperación de información en los archivos fotográficos: un estado de la cuestión (2006-2007). Facultad de Ciencias de la Comunicación, UAB.

http://www.cobdc.org/aldia/pdf/treballpremi2008.pdf

Casellas-Serra, Lluís-Esteve; Iglesias-Franch, David. "Nuevas tecnologías y tratamiento de fondos y colecciones fotográfi- cas". Il Jornadas imagen, cultura y tecnología. Madrid: Universidad Carlos III, 2003.

http://www.girona.cat/sgdap/docs/uc3m.pdf

Codina, Lluís. "Obtención, edición y gestión de imágenes mediante recursos de libre acceso". El profesional de la información, 2007, septiembre-octubre, v. 16, n. 5, pp. 512517.

http://dx.doi.org/10.3145/epi.2007.sep.15

http://www.elprofesionaldelainformacion.com/conteni dos/2007/septiembre/15.pdf

Del-Valle-Gastaminza, Félix. "El análisis documental de la fotografía". Cuadernos de documentación multimedia, junio 1993, v. 2, pp. 43-56.

Marcos, Mari-Carmen. "Balance de la primera jornada de documentación audiovisual". El profesional de la información, 2003, marzo-abril, v. 12, n. 2, pp. 160-164.

http://www.elprofesionaldelainformacion.com/conteni dos $/ 2003 /$ marzo/18.pdf

Pasini, Mike. "iView MediaPro - What the pros use". Imaging resource.

http://www.imaging-resource.com/SOFT/IVM/IVM.HTM

Ruiz-Rodríguez, Antonio. "Patrimonio, fotografía de prensa y metadatos". I Jornadas de imagen, cultura y tecnología. Madrid: Universidad Carlos III, 2002, pp. 259-275.

http://e-archivo.uc3m.es/bitstream/10016/8947/1/patri monio_ruiz_ICT_2002.pdf

Sánchez-Vigil, Juan-Miguel. "Archivos fotográficos de prensa". Cuadernos de documentación multimedia, 2002.

Sánchez-Vigil, Juan-Miguel. "Automatización de los archivos fotográficos. Modelos de fin de siglo: Oronoz y Scala. Biblios, 2002, julio-septiembre, v. 4, n. 13. http://redalyc.uaemex.mx/pdf/161/16113406.pdf

Serra-Serra, Jordi. Los documentos electrónicos. Qué son y cómo se tratan. Gijón, Ediciones Trea, 2008.

\section{Próximos temas centrales}

Septiembre 2011

Noviembre 2011

Enero 2012

Marzo 2012

Mayo 2012

Julio 2012

Septiembre 2012

Noviembre 2012
Inteligencia competitiva

Fuentes de información 2.0

El futuro de la Web

Publicaciones científicas y acceso abierto

Organización del conocimiento

Comunicación digital

Información y derecho

Bibliotecas académicas

Los interesados pueden remitir notas, artículos, propuestas, publicidad, comentarios, etc., sobre estos temas a: http://recyt.fecyt.es/index.php/EPI/index 


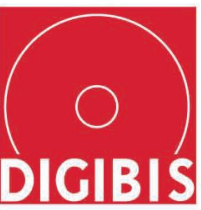

\section{Creación de Archivos y Bibliotecas Virtuales}

\section{Desde la digitalización de materiales bibliográficos hasta la asignación de} metadatos y su implementación en la red, conforme a la normativa internacional.
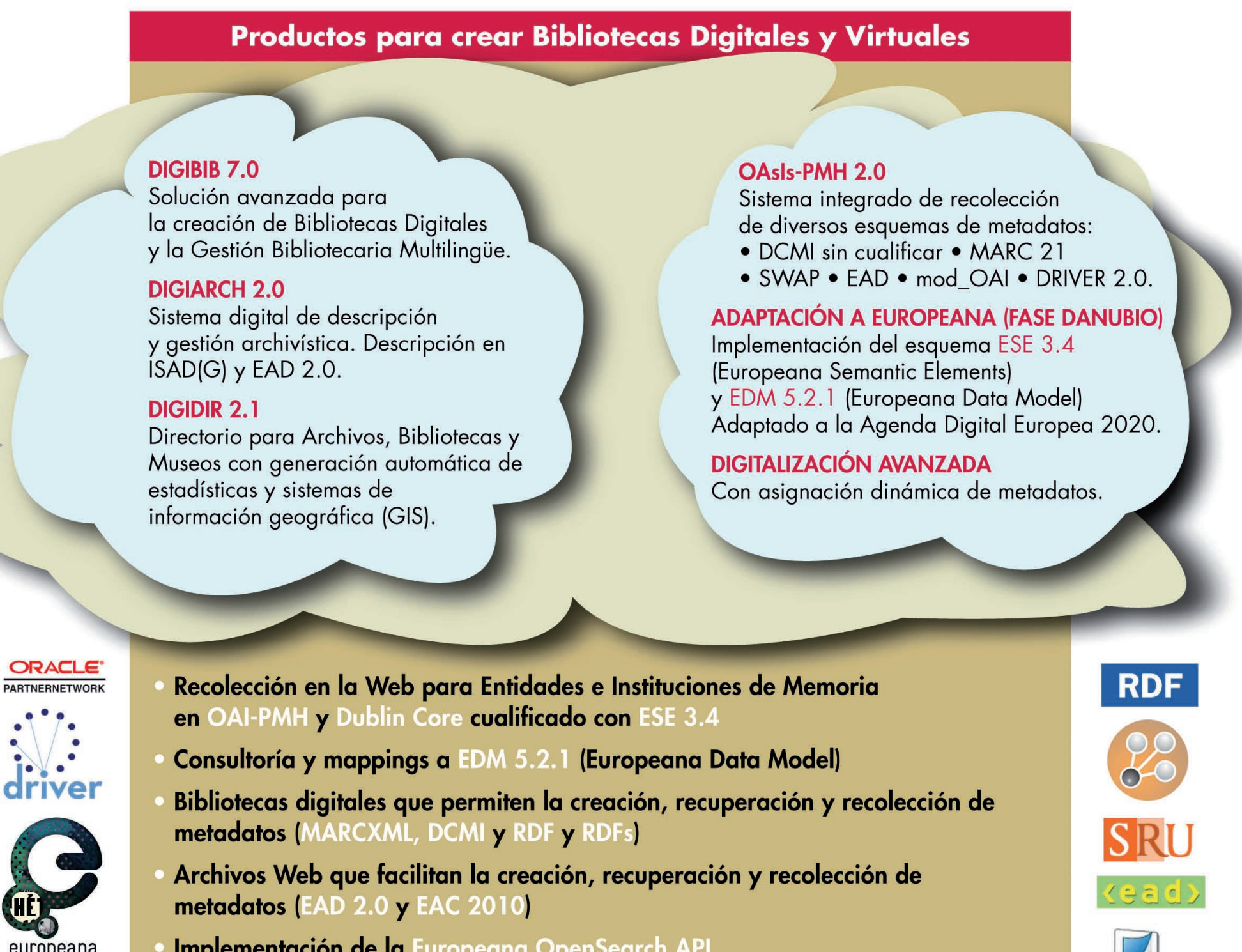

- Recolección en la Web para Entidades e Instituciones de Memoria en OAI-PMH y Dublin Core cualificado con ESE 3.4

- Consultoría y mappings a EDM 5.2.1 (Europeana Data Model)

- Bibliotecas digitales que permiten la creación, recuperación y recolección de metadatos (MARCXML, DCMl y RDF y RDFs)

- Archivos Web que facilitan la creación, recuperación y recolección de metadatos (EAD 2.0 y EAC 2010)

- Implementación de la Europeana OpenSearch API

Adaptación del repositiro OAl para la transmisión de instancias RDF según ORE

- Repositorios Institucionales DIGIPRESV para Preservación Digital a largo plazo mediante PREMIS 2.1 y OAIS ISO 14721

- Intercambio de metadatos en MEIS 1.9 (diferentes Profiles) integrando todos los esquemas de metadatos

Creación de MEISRights para el control de los derechos de autor

- Reconocimiento Óptico de Caracteres OCR y generación dinámica de ALTO (Analyzed Layout and Text Object)

- Generación e integración de registros SKOS mediante MARC21(Up. 12)/RDA

- Creación de eBooks o libros digitales en formatos: ePub y Mobipocket.

Adaptación de DIG|B|B a linked Open Doita

Validación en el Data Providers de la Open Archives Intiative. Genera un Sitemap para Google.

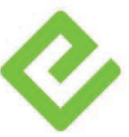

